\title{
Printability and structural analysis of yttrium iron garnet thick film with low firing temperature
}

\begin{abstract}
This paper presents results of study on Yttrium iron garnet (YIG) thick film paste using linseed oil as organic binder. YIG nanopowder is mixed with organic vehicle which consists of linseed oil, m-xylene and Üterpineol. Samples with different ratios of compositions are prepared to study the printability and adhesion properties of the paste. Paste samples were then screen printed onto alumina substrate, dried and fired at $300^{\circ} \mathrm{C}$. Microscopic images of the samples were observed to determine most suitable ratio for producing YIG paste. Based on the results, YIG paste with $30 \mathrm{wt} \%$ ratio showed good adhesion to the substrate as well as having high dielectric property compared to pastes with lower powder ratio.
\end{abstract}

Keyword: Linseed oil; Organic vehicle; Screen printing; Thick film; Yttrium iron garnet 